\title{
MODUL MATEMATIKA BERBASIS MODEL KOOPERATIF TIPE STAD DENGAN METODE PENEMUAN TERBIMBING PADA POKOK BAHASAN TEOREMA PHYTAGORAS
}

\author{
Yulia Rahmadani ${ }^{1}$, Thamrin Tayeb ${ }^{2}$, Baharuddin ${ }^{3}$ \\ 1,2,3Fakultas Tarbiyah dan Keguruan UIN Alauddin Makassar \\ 1,2,3Kampus II: Jl. H.M. Yasin Limpo Nomor 36 Samata-Gowa \\ Email: yuliarahmadani94@yahoo.com ${ }^{1}$, thamrinthayeb@yahoo.com ${ }^{2}$, bohe.nuny@gmail.com³
}

\begin{abstract}
Abstrak:
Penelitian ini bertujuan untuk mengetahui proses pengembangan dan menilai kualitas bahan ajar matematika berbasis model kooperatif tipe STAD dengan metode penemuan terbimbing pada pokok bahasan teorema Phytagoras yang valid, praktis, dan efektif. Jenis penelitian yang digunakan adalah penelitian research \& development (R\&D) dengan mengacu pada model 4-D (Four D models). Berdasarkan hasil uji coba terbatas yang dilakukan, diperoleh bahwa (a) hasil validasi bahan ajar adalah 3,50 pada kategori valid karena setiap aspek untuk setiap jenis perangkat berada pada interval $3 \leq M<4$, (b) hasil pengamatan keterlaksanaan bahan ajar matematika berbasis model kooperatif tipe STAD dengan metode penemuan terbimbing adalah 1,89 menunjukkan bahwa komponen pengamatan keterlaksanaan berada pada kategori terlaksana seluruhnya (praktis) atau berada pada interval $1,5 \leq \bar{X} \leq 2$, (c) dari keempat kriteria keefektifan yaitu, kemampuan guru mengelola pembelajaran, keterlaksanaan bahan ajar bagi siswa, respon siswa dan tes hasil belajar, dapat disimpulkan bahwa pada tahap uji coba terbatas dilaksanakan, perangkat bahan ajar matematika berbasis model kooperatif tipe STAD dengan metode penemuan terbimbing telah memenuhi kriteria kevalidan, kepraktisan, dan keefektifan.
\end{abstract}

\begin{abstract}
:
The study was a developmental research aiming at determining the process of developing and assessing the quality of teaching materials based on cooperative model of STAD type with guided discovery method on valid, practical, and effective Pythagoras theory subject. The type of research used was Research $\mathcal{E}$ Development (RED) by referring to the 4-D model (Four D Models). The subjects of the study were the students of class VIII 7 MTsN Model Makassar with a total of 40 students. Based on the results of the limited trial conducted, it was found that (a) the validation result of the teaching materials was 3.50 in the valid category as every aspect for each type of device was at the interval of $3 \leq M<4$, (b) the observation result of the implementation of mathematics teaching materials based on cooperative model of STAD type with guided discovery method was 1.89 indicating that the observation component of the implementation was in the category of executed entirely (practically) or it was at the interval of $1.5 \leq X \leq 2$, (c) of the four criteria of effectiveness that was, the teacher's ability to manage the learning, the implementation of
\end{abstract}


teaching materials for students, the students' responses and learning result test, it can be concluded that at the limited trial stage implemented, the mathematics learning materials based on cooperative model of STAD type with guided discovery method had fulfilled the criteria of validity, practicality and effectiveness.

\section{Kata kunci:}

Bahan Ajar, Model Kooperatif tipe STAD, Metode Penemuan Terbimbing

PENDIDIKAN merupakan kebutuhan manusia sepanjang hidup dan selalu berubah lantaran mengikuti perkembangan zaman, teknologi, dan budaya masyarakat. Didalam Pembukaan UUD 1945 dinyatakan bahwa tujuan membentuk Negara Kesatuan Republik Indonesia ialah untuk mencerdaskan kehidupan bangsa. Undangundang Nomor 20 tahun 2003 tentang Sistem Pendidikan Nasional menegaskan bahwa pendidikan adalah usaha sadar dan terencana untuk mewujudkan suasana belajar dan proses pembelajaran agar peserta didik secara aktif mengembangkan potensi dirinya untuk memiliki kekuatan spiritual keagamaan, pengendalian diri, kepribadian, kecerdasan, akhlak mulia, serta keterampilan yang diperlukan oleh dirinya, masyarakat bangsa dan negara (Kadir, 2012: 34). Peningkatan sumber daya manusia berkaitan erat dengan pendidikan formal. Berbagai upaya telah dilakukan pemerintah untuk meningkatkan mutu pendidikan seperti perubahan kurikulum, pemantapan proses belajar mengajar, penyempurnaan sistem penilaian, penataran guru-guru, serta usaha-usaha lain yang berkaitan dengan peningkatan mutu pendidikan. Tujuan pendidikan kemudian diimplementasikan dalam kurikulum. Indonesia baru saja mengganti Kurikulum Tingkat Satuan Pendidikan (KTSP) dengan kurikulum 2013. Isu terhangat saat ini adanya penyempurnaan kurikulum KTSP menjadi kurikulum 2013 yang mendapatkan pro dan kontra dari berbagai pihak baik dari kalangan pendidikan maupun dari masyarakat umum. Kurikulum 2013 justru dianggap dapat memasung kreativitas dan otonomi di bidang pendidikan karena kurikulum dan persiapan proses pembelajaran akan disediakan dalam bentuk produk jadi (completely-built up product). Di sisi lain, sebagian orang beranggapan justru dengan adanya kurikulum 2013 dapat memicu pengembangan kompetensi siswa kearah yang lebih analisis dan tuntutan guru agar lebih kreatif dan inovatif dalam pembelajaran karena guru dianggap mampu semua hal yang dapat membantu siswa berkembang (Idi, 2014: 90). Kurikulum 2013 bertujuan untuk mempersiapkan manusia Indonesia agar memiliki kemampuan hidup sebagai pribadi dan warga negara yang beriman, produktif, kreatif, inovatif, dan afektif serta mampu berkontribusi pada kehidupan bermasyarakat, berbangsa, bernegara, dan peradaban dunia. Proses pembelajaran pada kurikulum 2013 untuk semua jenjang dilaksanakan dengan menggunakan metode penemuan terbimbing yaitu dimana dengan metode ini dominasi pembelajaran di kelas adalah dominasi siswa. Peran guru adalah fasilitator, serta pada saat menyiapkan perangkat pembelajaran berupa modul. Hal ini dikarenakan, metode discovery atau metode penemuan terbimbing adalah metode mengajar yang mengatur pengajaran sedemikian rupa sehingga anak memperoleh pengetahuan yang 
sebelumnya belum diketahuinya itu tidak melalui pemberitahuan, sebagian atau seluruhnya ditemukan sendiri. Diharapkan, jika siswa terlibat aktif dalam menemukan pola dan struktur matematika itu, siswa akan memahami konsep dan teorema lebih baik, ingat lebih lama dan mampu mengaplikasikannya ke situasi yang lain dan akan membawa siswa ingin mengetahui lebih lanjut hubungan dan struktur yang ditemukan.

Kurikulum adalah seperangkat rencana dan pengaturan mengenai tujuan, isi, dan bahan pelajaran serta cara yang digunakan sebagai pedoman penyelenggaraan kegiatan pembelajaran untuk mencapai tujuan pendidikan tertentu (Purboningsih, 2015: 148). Setiap kurikulum memiliki ciri khas dan karakteristik sendiri-sendiri. KTSP adalah kurikulum operasional yang disusun dan dilaksanakan di masingmasing satuan pendidikan, sedangkan kurikulum 2013 merupakan bagian dari melanjutkan pengembangan Kurikulum Berbasis Kompetensi (KBK) yang telah dirintis pada tahun 2004 dengan mencakup kompetensi sikap, pengetahuan, dan keterampilan secara terpadu. Kurikulum 2013 dan KTSP mempunyai perbedaan seperti KTSP mata pelajaran yang dirancang berdiri sendiri dan memiliki kompetensi dasar sendiri, sedangkan kurikulum 2013 mata pelajaran yang dirancang terkait satu dengan yang lain dan memiliki kompetensi dasar yang diikat oleh kompetensi inti tiap kelas. Selain itu perbedaan lain terlihat pada kurikulum KTSP siswa SMA ada penjurusan sejak kelas XI sedangkan kalau kurikulum 2013 siswa SMA tidak ada penjurusan SMA. Ada mata pelajaran wajib, peminatan, antar minat, dan pendalaman minat.

Pada umumnya, matematika sering dianggap sebagai mata pelajaran yang sulit dipahami. Hal ini bisa dikarenakan berbagai faktor. Secara garis besar, faktor-faktor tersebut dapat dibedakan menjadi dua yaitu: faktor intern dan faktor ekstern. Faktor internal yaitu berupa motivasi, kesehatan, bakat, intelegensi dan kemampuan yang dimiliki peserta didik. Sedangkan faktor ekstern yaitu berupa fasilitas belajar, sarana dan prasarana sekolah, guru, orang tua, media pendidikan dan metode mengajar yang digunakan oleh seorang guru. Hal ini dikarenakan peran guru didalam pembelajaran merupakan seorang fasilitator, moderator, dan evaluator, sedangkan siswa berfikir, mengkomunikasikan alasannya, melatih nuansa demokrasi dengan menghargai pendapat orang lain. Untuk meningkatkan hasil belajar matematika maka pemilihan pengajaran yang tepat dapat membantu pengajaran dalam kelas, salah satunya dengan menggunakan pembelajaran kooperatif tipe STAD (Student Teams Achievement Division) (Purboningsih, 2015). Pembelajaran kooperatif ini mencakup suatu kelompok kecil siswa yang bekerja sebagai sebuah tim untuk menyelesaikan suatu masalah, menyelesaikan suatu tugas atau mengerjakan sesuatu untuk mencapai tujuan pembelajaran dan hasil belajar.

Berdasarkan hasil wawancara dan observasi yang dilakukan di MTsN Makassar, khususnya dalam pembelajaran matematika diperoleh masalah yaitu bahan ajar yang tersedia masih terbatas dan belum menggunkan model pembelajaran yang menarik dan memudahkan peserta didik. Materi teorema Phytagoras yang disajikan di dalam buku paket siswa terbatas dan mencakup intinya saja, selain itu 
contoh soal yang terdapat dalam buku paket siswa sangat terbatas sehingga masih banyak siswa yang kesulitan dalam memahami materi. Pada umumnya peserta didik mengalami kesulitan dalam menguasai materi ini, karena materi teorema Phytagoras merupakan syarat akan konsep, prinsip, dan penerapan konsep-konsep. Hal ini terlihat ketika guru memberikan soal aplikasi.

Dalam penelitian ini dengan menggunakan pembelajaran kooperatif tipe STAD (Student Teams Achievement Division). Pembelajaran kooperatif ini mencakupi suatu kelompok kecil siswa yang bekerja sebagai sebuah tim untuk menyelesaikan suatu masalah, menyelesaikan suatu tugas atau mengerjakan sesuatu untuk mencapai tujuan pembelajaran dan hasil belajar dapat ditingkatkan (Esminarto, Sukowati, Suryowati, N., Anam, K., 2015), sedangkan metode penemuan terbimbing adalah metode mengajar yang mengatur pengajaran sedemikian rupa sehingga anak memperoleh pengetahuan yang sebelumnya belum diketahuinya, tidak melalui pemberitahuan, sebagian atau seluruhnya ditemukan sendiri (Hajerina, 2017). Diharapkan, jika siswa terlibat aktif dalam menemukan pola dan struktur matematika itu, siswa akan memahami konsep dan teorema lebih baik, ingat lebih lama dan mampu mengaplikasikannya ke situasi yang lain dan akan membawa siswa ingin mengetahui lebih lanjut hubungan dan struktur yang ditemukan. Dengan kondisi pembelajaran yang demikian dibutuhkan sebuah alat dalam pembelajaran yang diharapkan dapat mengatasi permasalahan tersebut. Pengembangan modul dalam dunia pendidikan merupakan suatu solusi untuk membantu siswa dan guru dalam pembelajaran matematika yang bertujuan untuk meningkatkan kemampuan siswa dalam memahami materi khususnya materi teorema Phytagoras. Apabila peserta didik telah mampu menguasai konsep teorema Pythagoras maka siswa akan lebih mudah menyelesaikan soal-soal yang berkaitan dengan teorema Pythagoras, meskipun soal-soal tersebut dimodifikasi (Zaerani, Mardhiah, \& Suharti, 2017). Hal-hal yang perlu dikembangkan pada modul tersebut seperti materi, soal dan contoh perlu ditambahkan yang berhubungan dengan kehidupan sehari-hari, serta tambahan kata-kata berupa motivasi agar siswa termotivasi untuk belajar. Diharapkan dengan penambahan hal-hal tersebut dapat melatih siswa memecahkan masalahnya sendiri sehingga tujuan pembelajaran yang diharapkan dapat tercapai dengan hasil yang memuaskan.

Berdasarkan masalah tersebut, maka penulis ingin mengembangkan bahan ajar modul sehingga dapat menunjang kekurangan yang terdapat pada bahan ajar berupa buku paket yang saat ini di terapkan disana. Penelitian ini berjudul pengembangan bahan ajar matematika berbasis model kooperatif tipe STAD dengan metode penemuan terbimbing pada pokok bahasan teorema Phytagoras. Penelitian relevan telah dilakukan oleh Nurhidayati, Tayeb, \& Baharuddin (2017) dan Munawarah (2017) menghasilkan perangkat pembelajaran yang valid, praktis, dan efektif. Selain itu, penelitian ini bertujuan untuk mengetahui proses pengembangan dan menilai kualitas bahan ajar matematika berbasis model kooperatif tipe STAD dengan metode penemuan terbimbing pada pokok bahasan teorema Phytagoras yang valid, praktis, dan efektif. 


\section{METODE PENELITIAN}

Penelitian ini merupakan penelitian pengembangan atau sering disebut dengan penelitian Research $\mathcal{E}$ Development (R\&D) dengan mengadaptasi model pengembangan 4-D (define, design, develop, and dessminate). Produk yang akan dikembangkan dalam penelitian ini adalah bahan ajar berupa modul matematika berbasis model kooperatif tipe STAD dengan metode penemuan terbimbing pada pokoks bahasan teorema phytagora kelas VIII MTsN Model Makassar. Dengan Subjek coba yaitu siswa kelas VIII 7 MTsN Model Makassar. Instrumen pengumpulan data yang digunakan dalam penelitian ini adalah: (1) untuk mengukur kevalidan yaitu dengan menggunakan lembar validasi ahli, (2) untuk mengukur kepraktisan yaitu dengan menggunakan lembar observasi keterlaksanaan bahan ajar, dan (3) untuk mengukur keefektifan yaitu dengan menggunakan lembar observasi kemampan guru mengelola pembelajaran, angket respon siswa, lembar observasi aktivitas siswa dan tes hasil belajar (THB).

Berikut ini di kemukakan tentang analisis data kevalidan, kepraktisan dan keefektifan.

Tabel 1. Data Kevalidan, Kepraktisan dan Keefektifan

\begin{tabular}{l}
\hline Kevalidan \\
\hline 1. Mencari rata-rata perbutir \\
dari validator dengan \\
menggunakan rumus: \\
$\overline{B l}=\frac{\sum_{h=1}^{n} V_{h i}}{n}$, dengan: \\
$\overline{B l}=$ rata-rata perbutir \\
$V_{h i}=$ skor hasil penilaian \\
$n=\quad$ banyaknya \\
\end{tabular}

2. Mencari rata-rata tiap sub komponen dengan menggunakan rumus: $\overline{S l}=\frac{\sum_{j=1}^{n} \overline{B \imath \jmath}}{n}$, dengan : $\overline{S_{l}}=$ rata-rata subkomponen ke-i $\overline{B l \jmath}=$ rata-rata untuk subkomponen ke-i oleh butir ke-j $n=$ banyaknya butir dalam subkomponen ke-i

3. Mencari rata-rata tiap komponen dengan menggunakan rumus: $\overline{K \iota}=\frac{\sum_{i=1}^{n} \overline{A l}}{n}$, dengan :

\section{Kepraktisan}

Data kepraktisan perangkat bahan ajar berbasis model kooperatif tipe STAD dengan metode penemuan terbimbing diperoleh melalui data dari pengamatan keterlaksanaan bahan ajar berbasis model kooperatif tipe STAD dengan metode penemuan terbimbing secara umum. Pada analisis data keterlaksanaan bahan ajar berbasis model kooperatif tipe STAD dengan metode penemuan terbimbing, kriteria yang digunakan

\section{Keefektifan}

Tes hasil belajar dengan rumus :

$$
K B=\frac{T}{T_{1}} \times 100 \%
$$

Keterangan :

$\mathrm{KB}=$ Ketuntasan Belajar

$\mathrm{T}=$ Jumlah skor yang

diperoleh siswa

$T_{1}=$ Jumlah skor total

Angket repon siswa

dilakukan dengan

Menghitung banyak siswa yang memberi respon positif terhadap pertaanyaan atau pernyataan dari setiap aspek, dengan kategori "negatif" yaitu kriteria 1 dan 2 dan kategori "positif" yaitu kriteria 3 dan 4

Aktivitas siswa dilakukan dengan menggunakan rumus:

$\mathrm{PT} \alpha=\frac{\sum T A}{\sum T} \times 100 \%$ 
$\overline{K \iota}=$ rata-rata total

$\overline{A l}=$ rata-rata untuk aspek ke-i

$n$ = banyaknya aspek

4. Mencari rata-rata total validitas semua komponen menggunakan rumus:

$\overline{R T V}=\frac{\sum_{j=1}^{n} \overline{K \iota}}{n}$, dengan : $\overline{R T V}=$ rata-rata total validitas buku ajar $\overline{K \iota}=$ rata-rata komponen ke-i

$$
\begin{aligned}
& n=\quad \text { banyaknya } \\
& \text { komponen }
\end{aligned}
$$

5. Menentukan kategori kevalidan dengan mencocokkan rata-rata total dengan kriteria kevalidan:

$4 \leq \boldsymbol{R T} \boldsymbol{V} \leq 5 \rightarrow$ sangat

valid

$3 \leq \boldsymbol{R T V}<4 \rightarrow$ valid

$2 \leq \boldsymbol{R T V}<3 \rightarrow$ kurang

valid

$1 \leq \boldsymbol{R T V}<2 \rightarrow$ kurang valid untuk memutuskan

bahwa berbasis

model kooperatif

tipe STAD dengan

metode penemuan

terbimbing

memiliki tingkatan

keterlaksanaan

yang memadai

adalah $\bar{X}$ minimal

berada dalam

kategori terlaksana

sebagian, berarti

model tidak

direvisi.

$$
\begin{aligned}
& \text { Keterangan : } \\
& P T \alpha= \text { Persentase } \\
& \text { aktivitas peserta } \\
& \text { didik untuk } \\
& \text { melakukan suatu } \\
& \text { jenis aktivitas } \\
& \text { tertentu } \\
& \Sigma T A= \text { jumlah jenis } \\
& \text { aktivitas peserta } \\
& \text { didik yang } \\
& \text { dilakukan setiap } \\
& \text { pertemuan } \\
& \Sigma T= \text { jumlah seluruh } \\
& \text { aktivitas peserta } \\
& \text { didik }
\end{aligned}
$$

Kemampuan guru mengelola pelajaran, yang dilakuakan adalah berdasarkan hasil pengamatan di setiap pertemuan di rekap sehingga terkumpul semua skor setiap kriteria pengamatan pengelolaan pembelajaran dan kemudian dihitung rataratanya. Langkah berikutnya adalah menentuukan rata-rata tiap-tiap fase kegiatan pembelajaran berdasarkan rata-rata setiap pengamatan yang dihitung sebelumnya. Akhirnya berdasarkan rata-rata penilaian semua fase pengelolaan pembelajaran di tentukan nilai rata-rata total pengelolaan pembelajaran untuk kemudian di tentukan kemampuan guru mengelola pembelajaran dengan kategori $\boldsymbol{K} \boldsymbol{G} \geq 4,5 \rightarrow$ sangat tinggi 
$3,5 \leq K \boldsymbol{K} \leq 4,5 \rightarrow$ tinggi

$2,5 \leq \boldsymbol{K} \boldsymbol{G} \leq$

$3,5 \rightarrow$ sedang/cukup

$1,5 \leq \boldsymbol{K} \boldsymbol{G} \leq 2,5 \rightarrow$ rendah

\section{HASIL PENELITIAN DAN PEMBAHASAN}

Adapun hasil validasi bahan ajar ditampilkan pada tabel 2 berikut.

Tabel 2. Rangkuman Hasil Uji Kevalidan

\begin{tabular}{ccc}
\hline Sumber & Skor Rata-rata & Kriteria \\
\hline Modul & 3.50 & Valid \\
RPP & 3 & Valid \\
THB & 3.75 & Valid \\
Aktivitas Siswa & 4 & Valid \\
Keterlaksanaan Bahan Ajar & 4.166 & Sangat Valid \\
Respon Siswa & 4.5 & Sangat Valid \\
Kemampuan Guru Mengelola & 4 & Valid \\
Pembelajaran & & \\
\hline
\end{tabular}

Berdasarkan tabel di atas, dapat disimpulkan bahwa hasil validasi bahan ajar adalah 3.50 pada kategori valid karena setiap aspek untuk setiap jenis perangkat berada pada interval $3 \leq X<4$.

Tabel 3. Rangkuman Hasil Uji Kepraktisan

\begin{tabular}{cccc}
\hline No. & Lembar Penilaian Komponen & Penilaian & Kategori \\
\hline 1. & Sintaks & 1,87 & Terlaksana Seluruhnya \\
2. & Interaksi Sosial & 1,97 & Terlaksana Seluruhnya \\
3. & Prinsip Reaksi & 1,83 & Terlaksana Seluruhnya \\
\hline \multicolumn{2}{l}{ Rata-rata Total Kepraktisan Instrument } & 1,89 & Terlaksana Seluruhnya \\
\hline
\end{tabular}

Berdasarkan tabel diatas, dapat disimpulkan bahwa bahan ajar berbasis model kooperatif tipe STAD dengan metode penemuan terbimbing adalah praktis, karena rata-rata semua komponen pengamatan keterlaksanaan bahan ajar adalah 1,89 pada kategori terlaksana seluruhnya atau berada pada interval $1,5 \leq \bar{X} \leq 2$.

Tabel 4. Hasil Belajar Pada Materi Persamaan dan Pertidaksamaan Linear Satu Variabel

\begin{tabular}{cccc}
\hline Skor & Kategori & Frekuensi & Persentase (\%) \\
\hline $85-100$ & Sangat Tinggi & 32 & $80 \%$ \\
$65-84$ & Tinggi & 5 & $12.5 \%$ \\
$55-64$ & Sedang & 1 & $2.5 \%$ \\
$35-54$ & Rendah & 2 & $5 \%$ \\
$0-34$ & Sangat Rendah & 0 & $0 \%$ \\
\hline
\end{tabular}




\begin{tabular}{ccc}
\hline Jumlah & 40 & $100 \%$ \\
\hline
\end{tabular}

Berdasarkan tabel diatas, dapat disimpulkan bahwa dari 40 siswa yang mengikuti tes hasil belajar terdapat $80 \%$ siswa dalam kategori sangat tinggi, $12.5 \%$ masuk dalam kategori tinggi, 2.5\% masuk dalam kategori sedang, 5\% masuk dalam kategori rendah. Hal ini menunjukkan bahwa siswa memperoleh pemahaman yang bervariasi terhadap materi yang disajikan dengan menggunakan bahan ajar berdasarkan model kooperatif tipe STAD dengan metode penemuan terbimbing. Namun, dari data tersebut dapat diketahui bahwa pemahaman siswa cenderung sangat tinggi atau tinggi.

Tabel 5. Deskripsi Ketuntasan Pencapaian Hasil Belajar Siswa

\begin{tabular}{cccc}
\hline Skor & Kategori & Frekuensi & Persentase (\%) \\
\hline $0.0-74.00$ & Tidak Tuntas & 5 & $12.5 \%$ \\
$75.00-100.00$ & Tuntas & 35 & $8.75 \%$ \\
\hline
\end{tabular}

Berdasarkan tabel diatas, dapat disimpulkan bahwa dari 40 siswa terdapat 35 siswa yang telah tuntas belajar. Dengan demikian, penguasaan tes hasil belajar siswa sudah memenuhi standar ketuntasan secara klasikal.

Tabel 6. Rangkuman Hasil Uji Keefektifan

\begin{tabular}{cclc}
\hline No. & Lembar Penilaian & \multicolumn{1}{c}{ Penilaian } & Kategori \\
\hline 1. & THB & $\begin{array}{l}\text { Hasil belajar siswa tercapai } \\
\text { karena } 88 \% \text { siswa mencapai } \\
\text { skor } 75\end{array}$ & Efektif \\
& & $\begin{array}{l}\text { Telah memenuhi kriteria batas } \\
\text { toleransi pencapaian waktu } \\
\text { 2. Aktivitas Siswa }\end{array}$ & Efektif \\
& & $\begin{array}{l}\text { ideal yang digunakan } \\
\text { Hasil respon siswa yaitu 100\% } \\
\text { 3. Angket Respon Siswa respon positif. }\end{array}$ & Efektif \\
\hline
\end{tabular}

Berdasarkan tabel tersebut, dapat disimpulkan bahwa bahan ajar berbasis model kooperatif tipe STAD dengan metode penemuan terbimbing adalah efektif karena telah memenuhi tiga dari empat kriteria yang menjadi acuan yaitu hasil belajar siswa tercapai karena $88 \%$ siswa mencapai skor 75, aktivitas siswa ideal, karena telah memenuhi kriteria batas toleransi pencapaian waktu ideal yang digunakan, dan hasil respon siswa adalah $100 \%$ pada kategori positif karena lebih dari 50\% siswa memberikan respon positif. Oleh karena itu, pada tahap uji coba terbatas, bahan ajar matematika berbasis model kooperatif tipe STAD dengan metode penemuan terbimbing pada pokok bahasan teorema Phytagoras kelas VIII MTsN Model Makassar telah memenuhi kriteria kevalidan, kepraktisan, dan keefektifan. 


\section{SIMPULAN}

Proses pengembangan bahan ajar dengan menggunakan model 4-D terdiri dari 4 tahap yaitu pendefenisian (define), perancangan (design), dan pengembangan (develop), dan tahap penyebaran (desseminate). Pada tahap pendefenisian (define) yang dilakukan antara lain (1) analisis awal akhir untuk mengidentifikasi masalah-masalah yang dihadapi oleh guru MTsN Model Makassar khususnya guru yang mengajar di kelas VIII, (2) analisis siswa untuk menelaah karakteristik peserta didik meliputi pengetahuan, keterampilan dan sikap awal yang dimiliki siswa, (3) analisis konsep, dengan menguraikan konsep-konsep yang harus ditemukan dan dipelajari oleh siswa dalam bahan ajar, (4) analisis tugas, menemukan dan membuktian teorema Phytagoras, penggunaan teorema, (5) spesifikasi tujuan pembelajaran, dilakukan dengan menjabarkan kompetensi dasar ke dalam indikator pencapaian hasil belajar yang lebih spesifik berdasarkan analisis materi dan analisis tugas. Tahap perancangan (design), peneliti mulai merancang bahan ajar berbasis model kooperatif tipe STAD dengan metode penemuan terbimbing pada materi teorema Phytagoras kelas VIII MTsN Model Makassar. Tahap pengembangan (develop),pada tahap ini peneliti melakukan validasi terhadap bahan ajar yang dibuat untuk memenuhi kriteria pertama pada bahan ajar yaitu valid, kemudian dilakukan uji coba untuk memenuhi kriteria kepraktisan dengan menggunakan lembar observasi keterlaksanaan bahan ajar, dan selanjutnya bahan ajar yang telah dikembangkan di uji keefektifannya dengan memenuhi kriteria efektif yaitu apabila memenuhi 3 dari 4 kriteria, dengan kriteria ketuntasan klasikalnya adalah (1) tes hasil belajar (THB), (2) aktivitas siswa, (3) kemampuan guru mengelola pembelajaran, (4) respon siswa terhadap bahan ajar. Sedangakan tahap penyebaran (disseminate) tidak dilakukan karena keterbatasan waktu dan biaya, dengan harapan akan dilanjutkan oleh peneliti selanjutnya. Berdasarkan hasil pengembangan bahan ajar diperoleh bahan ajar yang valid, praktis, dan efektif.

\section{DAFTAR PUSTAKA}

Delviati. (2014). Urgensi Penyusunan Bahan Ajar Oleh Guru. Haluan Media Group. Emzir. (2013). Metode Penelitian Pendidikan Kualitatif dan Kuantitatif. Jakarta: PT. Raja Grafindo Persada.

Esminarto, Sukowati, Suryowati, N., \& Anam. (2016). Implementasi Model STAD dalam Meningkatkan Hasil Belajar Siswa. Briliant: Jurnal Riset dan Konseptual, $1(1), 16-23$.

Hajerina. (2017). Penerapan Metode Penemuan Terbimbing untuk Meningkatkan Hasil Belajar Siswa. Pedagogy, 2(1), 99-160.

Idi, A. (2014). Pengembangan Kurikulum Teori dan Praktik. Jakarta: Radja Grafindo. Islawati. (2014). Pengembangan Modul Pembelajaran Kimia Berorientasi Problem Based Learning Pada Materi Larutan Penyangga Bagi Siswa XI IPA. Makassar. PPs UNM. Kadir, A. (2012). Dasar-dasar Pendidikan. Jakarta: Kencana Perdana Media Grup. Munawarah. (2017). Pengembangan Perangkat Pembelajaran Matematika dengan 
Menggunakan Pendekatan Kontekstual. MaPan : Jurnal Matematika dan Pembelajaran, 5(2), 236-250.

Nurhidayati, S., Tayeb T., \& Baharuddin. (2017). Pengembangan Bahan Ajar Matematika Berbasis Masalah untuk Memfasilitasi Pencapaian Kemampuan Penalaran Pada Pokok Bahasan Perbandingan Kelas VII MTsN Model Makassar. MaPan : Jurnal Matematika dan Pembelajaran, 5(2), 236-250.

Nurdin. (2005). Model Pembelajaran Matematika yang Menumbuhkan Kemampuan Metakognitif untuk Menguasai Bahan Ajar. Surabaya: UNESA.

Purboningsih, D. (2015). Pengembangan Kurikulum Teori dan Praktik.

Rusman. (2013). Model-model Pembelajaran: Mengembangkan Profesionalisme Guru. Jakarta: Raha Grafindo Persada.

Safei, Muhammad. (2011). Media Pembelajaran. Makassar . Alauddin University Perss. Sagala, S. (2011). Konsep dan Makna Pembelajaran. Bandung: Alfabeta.

Suhana, C. (2014). Konsep Strategi Pembelajaran. Cet. IV Edisi revisi; Bandung: PT Refika Aditama.

Sugiyono. (2013). Metode Penelitian Kualitatif Kuantitatif dan RED. Bandung: Alfabeta.

Syarif, M. (2015). Startegi Pembelajaran Teori dan Praktik di Tingkat Pendidikan Dasar. Jakarta: Radja Grafindo Persada.

Zaerani, S., Mardhiah, \& Suharti. (2017). Pengaruh Penguasaan Konsep Teorema Pythagoras Terhadap Kemampuan Menyelesaikan Soal-Soal Bangun Ruang Sisi Datar Pada Siswa Kelas VIII MTs Negeri Balang-balang. MaPan : Jurnal Matematika dan Pembelajaran, 5(2), 279-292.

Yoshi, G. (2013). Pengembangan Modul Pembelajaran Matematika Berbasis Learning Cycle Pada Materi Lingkaran Untuk Kelas VIII MTsN Pitalah Tahun Ajaran 2013/ 2014. Universitas Muhammadiyah Sumatera Barat: FMIA. 